\title{
Rescue of a Pancreatic Islet Graft After Steroid Therapy
}

Allogeneic islet transplantation can restore insulin secretion in patients suffering from type 1 diabetes. However, the majority of islet transplant recipients experience a gradual decline in graft function (1). Several studies have implicated immune rejection in the loss of grafted islets $(2,3)$. Recently, our group reported a decline in islet graft function in association with human leukocyte antigen (HLA) sensitization in an islet transplant recipient and the recovery of islet function after treatment with an anti-CD20 monoclonal antibody (4). In this report, we document the decline of islet function in an islet transplant recipient and the recovery of the graft after steroid bolus therapy.

The patient was a 43-year-old woman with a 37-year history of diabetes who underwent islet transplantation because of metabolic instability as part of a clinical trial (GRAGIL-TRIMECO). Tests for HLA antibodies using the Luminex technique were consistently negative for HLA classes I and II. The patient received a graft containing 7400 islet equivalents per kilogram body weight from a single donor by percutaneous intraportal infusion. A pretransplant complement-dependent $\mathrm{T}$ - and $\mathrm{B}$-cell cross-match was negative. Immunosuppression was achieved by treating the patient with tacrolimus (Prograf; Fujisawa, Osaka, Japan; 2 mg/day), mycophenolate mofetil (CellCept; Roche, Basel, Switzerland; $2 \mathrm{~g} /$ day), antithymocyte globulin (Thymoglobulin; Genzyme SAS, Saint-Germain-enLaye, France; total dose of $6 \mathrm{mg} / \mathrm{kg}$ ), and etanercept (Enbrel; Pfizer, Groton, CT; 50 mg intravenously at day 0 , then $25 \mathrm{mg}$ subcutaneously on days 3,5 , and 10) induction. Immediately after islet transplantation, fasting C-peptide levels increased from 0 to 1.2 $\mathrm{ng} / \mathrm{mL}$ (normal range: $0.8-3 \mathrm{ng} / \mathrm{mL}$ ). The patient was treated by subcutaneous insulin infusion with external pump, and the insulin requirements decreased slowly from 26 to 17 IU/day. One month after transplantation, a postprandial glucose peak greater than 11 $\mathrm{mmol} / \mathrm{L}$ was observed, with C-peptide levels decreasing to $0.3 \mathrm{ng} / \mathrm{mL}$ and an increase in
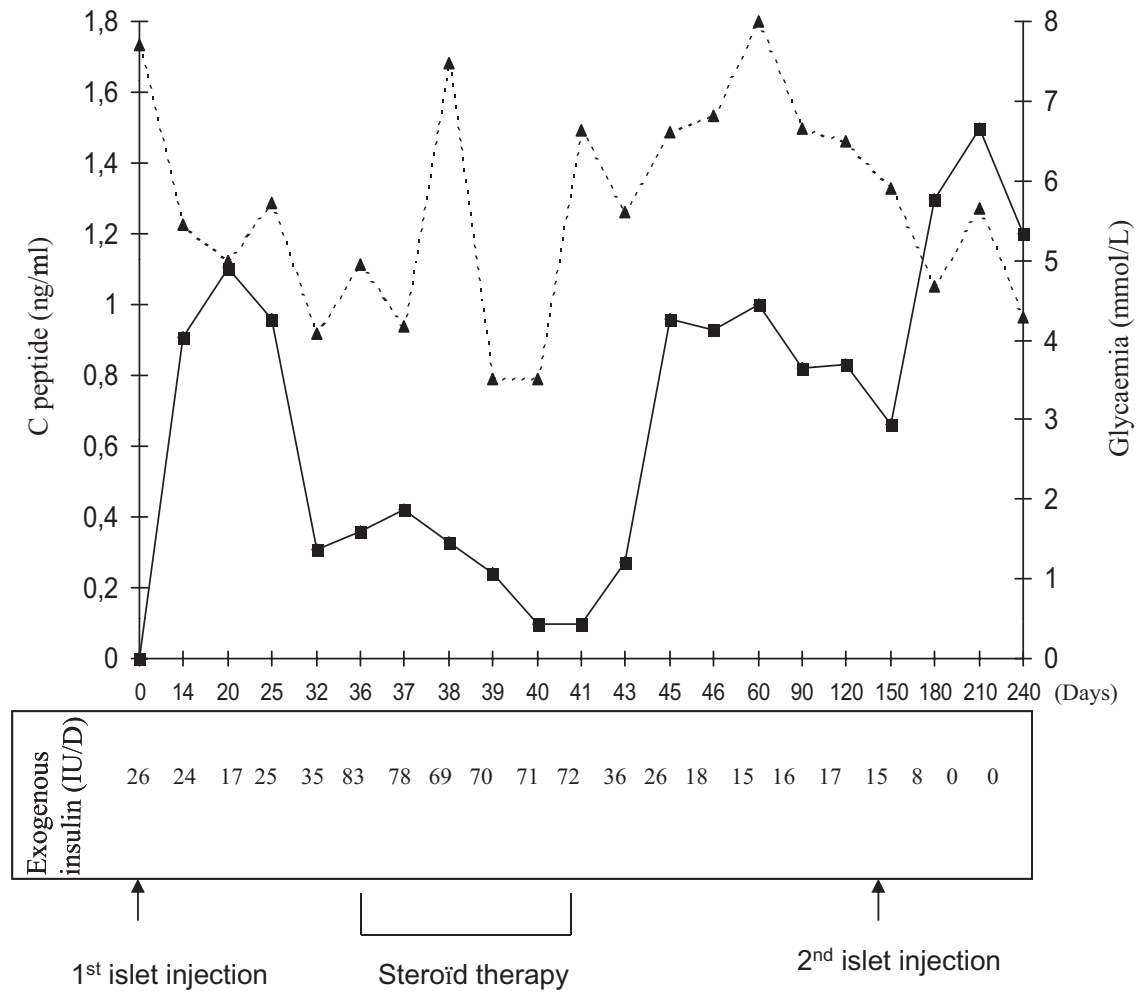

FIGURE 1. Fasting plasma C-peptide (-), blood glucose (- - - ) levels, and exogenous insulin needs in an islet transplant recipient before and after corticosteroid treatment.

insulin requirements to $30 \mathrm{IU} /$ day. Treatment with steroid boluses (methylprednisolone; Pfizer; $10 \mathrm{mg} / \mathrm{kg}$ for 3 days and then 6,4 and $2 \mathrm{mg} / \mathrm{kg}$ for 1 day) was initiated 4 days after the decrease in Cpeptide. Continuous intravenous insulin therapy (Umuline Rapide; Eli Lilly, Indianapolis, IN; 3-4.5 IU/hr) was administered to prevent hyperglycemia during the steroid therapy. Four days after steroid therapy, C-peptide levels were restored to $1.3 \mathrm{ng} / \mathrm{mL}$, with insulin requirements under external pump slowly decreasing from 35 to $15 \mathrm{IU} /$ day (Fig. 1). In the absence of an identified cause of islet loss, a diagnosis of acute cellular islet rejection was proposed. An assay for anti-HLA antibodies using the Luminex technique remained consistently negative for HLA classes I and II. In addi- tion, cross-matches performed with sera collected at the time of the graft dysfunction episode remained negative. No islet autoantibodies against glutamate acid decarboxylase 65 (GAD65) or IA-2 were detected. Tacrolimus trough levels were $11.5 \mu \mathrm{g} / \mathrm{L}$. There was no clinical or biological sign of infection. Polymerase chain reaction using primers specific for cytomegalovirus and Epstein-Barr virus yielded no detectable product. At 3 months after the first islet injection, the patient received a second islet graft of 6545 islet equivalents per kilogram body weight with basilixumab (Simulect, Novartis, Basel, Switzerland; $20 \mathrm{mg}$ intravenously at days 0 and 4) and etanercept (Enbrel; Pfizer) in induction. One month later, the patient was insulin-free and has remained so for 8 months. 
In this report, the recovery of islet function for at least 8 months after steroid bolus therapy strongly suggests acute islet rejection as the cause of the original decline in islet graft function. Biopsy is used to monitor all types of solid organ transplants and is the gold standard for the diagnosis of acute cellular rejection. However, in our case, we elected not to perform liver biopsy because of the low rate of success (31\%) of intraportal islet graft sampling by needle biopsy (5).

Despite tacrolimus trough levels in the therapeutic range, the abrupt loss of grafted islets in the early posttransplant period suggested an immune rejection process. However, in our patient, HLA antibodies, measured by the highly sensitive Luminex technique, remained consistently negative for HLA classes I and II. The cross-matches performed against donor cells with serum sampled during the decrease in C-peptide levels were also negative. Interestingly, steroid bolus therapy successfully salvaged rejecting islets after prompt administration. Indeed, corticosteroids are part of the armamentarium for maintenance of immune suppression for different kinds of transplanted organs, notably including pancreas transplantation $(6,7)$. Despite the well-documented negative effects of bolus steroid therapy on insulin-producing cells (8), the rescue of islet function strongly suggests reversal of acute cellular rejection of the islet graft.

In conclusion, an abrupt decline in islet function (without HLA sensitization) in the early period after islet transplantation and the rescue of islet graft by steroid therapy suggest acute cellular rejection of the islet graft. Steroid bolus therapy can salvage a rejected islet graft when administered promptly.

\section{ACKNOWLEDGMENTS}

The authors thank the procurement teams of the University Hospitals in Switzerland and France for their continuous efforts in this clinical islet transplantation program.

François Moreau $^{1}$ Florence Toti $^{2}$ François Bayle ${ }^{3}$ Thierry Berney ${ }^{4}$ Harald Egelhofer ${ }^{5}$ Maxime Chastre ${ }^{2}$ Marie Jeanne Richard ${ }^{5}$ Michel Greget $^{6}$ Dominique Masson ${ }^{5}$ Fatiha Zobairi ${ }^{2}$ Pierre-Yves. Benhamou ${ }^{7}$ Laurence Kessler ${ }^{1}$ on behalf of the GRAGIL group

${ }^{1}$ Department of Diabetology University of Strasbourg France

${ }^{2}$ Laboratory of Vascular Biology Immunology and Hematology Institute INSERM UMR 770

Faculty of Medicine University of Strasbourg and Paris-SUD 11 University

Faculty of Medicine Le Kremlin-Bicêtre, France ${ }^{3}$ Department of Nephrology University Hospital

Grenoble University, France

${ }^{4}$ Cell Isolation and Transplantation Center University Hospital Geneva, Switzerland ${ }^{5}$ Therapy Cellular Unit EFS-CHU Rhône Alpes La Tronche, France ${ }^{6}$ Department of Radiology University Hospital Strasbourg, France ${ }^{7}$ Department of Diabetology University Hospital Grenoble, France

The authors declare no funding or conflicts of interest.
Address correspondence to: Laurence Kessler, M.D., Ph.D., Department of Diabetology, Service d'Endocrinologie, Diabète et Maladies Métaboliques, Hôpital Civil 1, place de l'Hôpital, 67091-Strasbourg Cedex, France.

E-mail: laurence.kessler@chru-strasbourg.fr

F.M., H.E., M.J.R., M.G., D.M., and L.K. participated in the performance of the research; F.T., L.K., and T.B. participated in the writing of the manuscript; F.B., P.Y.B., and L.K. participated in research design.

Received 22 September 2011. Revision requested 11 October 2011.

Accepted 28 October 2011.

Copyright () 2012 by Lippincott Williams \& Wilkins

ISSN 0041-1337/12/9303-10

DOI: $10.1097 /$ TP.0b013e31823f7fb2

\section{REFERENCES}

1. Alejandro R, Barton FB, Hering BJ, et al. 2008 Update from the Collaborative Islet Transplant Registry. Transplantation 2008; 86: 1783.

2. Campbell PM, Senior PA, Salam A, et al. High risk of sensitization after failed islet transplantation. Am J Transplant 2007; 7: 2311.

3. Rickels MR, Kamoun M, Kearns J, et al. Evidence for allograft rejection in an islet transplant recipient and effect of B-cell secretory capacity. J Clin Endocrinol Metab 2007; 92: 2410.

4. Kessler L, Parissiadis A, Bayle F, et al. Evidence for humoral rejection of a pancreatic islet graft and rescue with rituximab and IV immunoglobulin therapy. Am J Transplant 2009; 9: 1961.

5. Toso C, Isse K, Demetris AJ, et al. Histologic graft assessment after clinical islet transplantation. Transplantion 2009; 88: 1286.

6. Volpin R, Angeli P, Galioto A, et al. Comparison between two high-dose methylprednisolone schedules in the treatment of acute hepatic cellular rejection in liver transplant recipients: A controlled clinical trial. Liver Transplant 2002; 8: 527.

7. Troxell ML, Koslin DB, Norman D, et al. Pancreas allograft rejection: Analysis of concurrent renal allograft biopsies and posttherapy follow-up biopsies. Transplantation 2010; 90: 75 .

8. Berney T, Buhler LH, Majno P, et al. Immunosuppression for pancreatic islet transplantation. Transplant Proc 2004; 36(suppl): S362.

\section{Successful Transplantation of Organs From a Donor With Postneurosurgical Meningitis Caused by Escherichia coli}

The scarcity of organs available for transplantation has led to the progressive broadening of criteria for accepting organs from donors deceased due to infections such as endocarditis and bacterial meningitis (1-8). Organ transplantation from donors dying from postneurosurgical Escherichia coli men- ingitis has only been reported in one case in the medical literature (3). We recently cared for a patient who met clinical criteria for brain death secondary to postneurosurgical meningitis caused by E. coli. The liver and kidneys were transplanted into three recipients. There was no donor-derived E. coli infection in the recipients.

\section{CASE REPORT}

A 56-year-old man was admitted to our hospital for urgent insertion of an external lumbar drain to divert cerebrospinal fluid caused by intraventricular hemorrhage. Six days after the neurosurgical procedure, he developed an altered level of consciousness, anisocoria, 